Please do not remove this page

RMIT

UNIVERSITY

\title{
Effect of low-intensity treadmill exercise on behavioural measures and hippocampal parvalbumin immunoreactivity in the rat
}

Nguyen, Jason; Killcross, Simon; Jenkins, Trisha

https://researchrepository.rmit.edu.au/esploro/outputs/9921859325701341/filesAndLinks?institution=61RMIT_INST\&index=null

Nguyen, J., Killcross, S., \& Jenkins, T. (2013). Effect of low-intensity treadmill exercise on behavioural measures and hippocampal parvalbumin immunoreactivity in the rat. Behavioural Brain Research, 256, 598-601. https://doi.org/10.1016/j.bbr.2013.09.004

Document Version: Accepted Manuscript

Published Version: https://doi.org/10.1016/j.bbr.2013.09.004

Repository homepage: https://researchrepository.rmit.edu.au

(C) 2013 Elsevier B.V. All rights reserved

Downloaded On 2023/04/26 20:02:12 +1000 
Thank you for downloading this document from the RMIT Research Repository.

The RMIT Research Repository is an open access database showcasing the research outputs of RMIT University researchers.

RMIT Research Repository: http://researchbank.rmit.edu.au/

\section{Citation:}

Nguyen, J, Killcross, S and Jenkins, T 2013, 'Effect of low-intensity treadmill exercise on behavioural measures and hippocampal parvalbumin immunoreactivity in the rat', Behavioural Brain Research, vol. 256, pp. 598-601.

See this record in the RMIT Research Repository at:

https://researchbank.rmit.edu.au/view/rmit:24044

Version: Accepted Manuscript

Copyright Statement: (C) 2013 Elsevier B.V. All rights reserved

Link to Published Version:

http://dx.doi.org/10.1016/j.bbr.2013.09.004 
We thank the reviewers for their poignant and constructive comments on our manuscript and address each of the comments and concerns below.

\section{Reviewer 1:}

Introduction:

'much' is deleted from the first line of the introduction.

\section{Methods:}

The treadmill used was a custom built 8 lane exercise treadmill with 5\% slope supplied by another investigator in Medical Sciences here at RMIT University, Professor John Hawley. Unlike some treadmills used in experimental procedures there was no aversive stimulus i.e. a shock apparatus if the animal slowed down or stopped running. Instead the rat slid off the back of the treadmill into a soft catchment area. We could then place the rat back on the treadmill. After piloting a number of speeds and timings we found that our rats would run for a maximum of 15 minutes before they began to have episodes of refusing to run. As such we exercised twice day as we were looking for a 30min/day training regime which was recommended by our animal ethics committee and Professor Hawley, an exercise physiologist, with numerous publications using this apparatus:

- Lessard SJ, Rivas DA, Stephenson EJ, Yaspelkis BB 3rd, Koch LG, Britton SL, Hawley JA. Exercise training reverses impaired skeletal muscle metabolism induced by artificial selection for low aerobic capacity. Am J Physiol Regul Integr Comp Physiol. 2011;300(1):R175-82.

- Yaspelkis BB 3rd, Kvasha IA, Lessard SJ, Rivas DA, Hawley JA.Aerobic training reverses high-fat diet-induced pro-inflammatory signalling in rat skeletal muscle. Eur J Appl Physiol. 2010;110(4):779-88.

- Rivas DA, Yaspelkis BB 3rd, Hawley JA, Lessard SJ. Lipid-induced mTOR activation in rat skeletal muscle reversed by exercise and 5'-aminoimidazole-4-carboxamide-1-beta-Dribofuranoside. J Endocrinol. 2009;202(3):441-51.

We have now included one of these references in the manuscript.

Results:

Figures 1 and 2 (now 3) have been amended (bolded font, thicker lines). An example of PV staining has been added to figure 3 .

Discussion:

1. As suggested by the reviewer we have elaborated on our elevated plus maze results in the discussion, furthering this to the anxiolytic effect of exercise, and indeed environmental enrichment (paragraph 4 of discussion).

2. As requested a figure of the elevated plus maze data has been included (now figure 2).

3. As recommended by the reviewer we have included some discussion on the possible association of PV staining and social behaviour.

4. Unfortunately we do not have any further brain sections from this cohort of animals to do further PV staining. However we believe that our hippocampal analysis demonstrates consistent findings with other researchers investigating this class of neurons and voluntary or treadmill exercise (Hwang, 2011;Arida, 2004;Gomes da Silva, 2010), thus replicating the effect of the intervention.

5. A more definite conclusion has been added.

\section{Reviewer 2:}

Major comments:

1. The reviewer was correct in that there was an error with figure 1. This has now been amended. All data has also been rechecked and is correct.

2. Control rats were handled for approximately five minutes each. This has been added to the methods. Indeed sitting the control rats on the stationary treadmill for the same amount of 
time as the exercising animals would be a very good idea. We thank the reviewer for this suggestion and will comply with this in the next study. Rats were run on the treadmill with their cage mates and thus the fellow runners were not novel. This detail has now been added to the methods.

3. We have chosen a low intensity exercise protocol for a number of reasons:

a. We were not interested in any kind of development in increased muscle physiology;

b. We were looking to in part model the exercise observed in an intervention like environmental enrichment;

c. As discussed above in the methods section of reviewer one after piloting a number of speeds and timings we found that our rats would run for a maximum of 15 minutes before they began to have episodes of refusing to run. As such we exercised twice day as we were looking for a $30 \mathrm{~min} /$ day training regime;

d. This regime was recommended by our animal ethics committee.

Minor comments:

1. Abbreviations and units of measure have been changed.

a. Metres have been changed to $\mathrm{m}$.

b. Minutes have been changed to min.

c. Hours have been changed to $h$.

d. CA2\&3 have been changed to CA2/3

e. + have been changed to plus

2. Time spent in the arms of the elevated plus maze amended in text to seconds

3. References have been amended. 
EFFECT OF LOW-INTENSITY TREADMILL EXERCISE ON BEHAVIOURAL MEASURES AND HIPPOCAMPAL PARVALBUMIN IMMUNOREACTIVITY IN THE RAT

\author{
${ }^{1}$ Jason C. D, Nguyen, ${ }^{2}$ A. Simon Killcross and ${ }^{1}$ Trisha A. Jenkins \\ ${ }^{1}$ School of Medical Sciences, Health Innovations Research Institute, RMIT University, Bundoora, \\ Victoria, 3083, Australia; and ${ }^{2}$ School of Psychology, University of New South Wales, Sydney, \\ New South Wales, 2052, Australia
}

Submitted to Behavioural Brain Research

Following review

\section{Corresponding author:}

Trisha A. Jenkins

School of Medical Sciences, Health Innovations Research Institute, RMIT University, Bundoora, Victoria, 3083, Australia trisha.jenkins@rmit.edu.au Phone: +61 399256523 Fax: +61 399257063 


\begin{abstract}
Exercise has been demonstrated to have positive effects on both the body and brain. The present study aimed to determine the behavioural and morphological consequence of low-intensity running. Rats were exercised on a treadmill for a total of 30days, 30min/day. Social interaction, locomotor activity and behaviour on an elevated plus maze were assessed post-treatment. Exercised animals demonstrated more passive interaction and less time not interacting than control animals that were not exercised. Conversely, locomotor and anxiety measures showed no effect of exercise. Analysis of brains demonstrated an increase in expression of parvalbumin immunoreactive neurons in the hippocampus localised to the CA1 and CA2/3 regions. These results demonstrate that low-intensity exercise leads to changes in social behaviour as well as neuroplastic morphological changes within the hippocampus.
\end{abstract}

\title{
Keywords
}

exercise, parvalbumin, hippocampus, anxiety, social interaction, locomotion 
While it is well recognised that exercise has numerous beneficial effects on the body, recent

research suggests that these positive effects also extend to the brain. Clinical studies indicate improvements in cognition in cognitively-normal [1] and impaired adults [2], with increases in brain volume, cerebral blood flow and functional brain plasticity observed. Much of these findings have been replicated in laboratory animals, demonstrating an important role of exercise in inducing positive brain changes in the rodent [3].

$\gamma$-aminobutyric acid (GABA)-ergic inhibitory neurons containing the calcium binding protein, parvalbumin, are suggested to be involved in various higher brain functions including emotion, anxiety, and learning and memory [4]. These neurons synapse on the cell body or axon initial segment of glutamatergic neurons and can regulate pyramidal cell output. Indeed a strong correlation has been demonstrated between the presence of parvalbumin and the fast firing properties of hippocampal neurons [5]. Parvalbumin containing GABAergic interneurons are effective markers of hippocampal cells [6] and are demonstrated to increase in number in the hilus of dentate gyrus in rats submitted to acute physical exercise [7].

The effect of exercise on so-called mood measures is less well understood. We know that exercise increases $\beta$-endorphin levels [8] and neurotransmitter release, including serotonin and dopamine [9, 10]. Behaviourally, regular moderate physical activity induces improvements in quality of life measures in normal adults and positively influences depressive symptoms in patients [11]. Positive social functioning is an important component of quality of life measures, and is often impaired in psychiatric disorders [12]. To date the social interaction test [13] is widely used by researchers to investigate animal social behaviour in response to novel interventions and treatments. The positive effects of exercise in this task are yet to be identified.

In the present study we evaluated the effect of exercise on social interaction in the rat, and assessed its effect on anxiety and locomotor measures. In addition, we determined if our exercise regime successfully induced morphological changes in the hippocampus, as per previous published reports $[7,14]$. 
Male Long-Evans rats ( $\mathrm{n}=19$, Monash University, Australia), weighing 221-271g were used for

experimental behavioural testing and subsequent brain analysis. A further 10 Long-Evans rats (Monash University, Australia), weighing 239-293g at the beginning of the study, were used as target animals for the social interaction task. Rats were housed 4-5 to a box under a $12 \mathrm{~h} \mathrm{light/} 12 \mathrm{~h}$ dark (lights on 6am) photoperiod cycle with food and water ad libutum in the home cage (57 long $\mathrm{x}$ $38 \mathrm{~cm}$ wide $\mathrm{x} 20 \mathrm{~cm}$ high). Room temperature $\left(21 \pm 1^{\circ} \mathrm{C}\right)$ and humidity $(30-70 \%)$ were kept constant. The experiments were performed in accordance with the Prevention of Cruelty to Animals Act 1986 and with approval from the RMIT University Animal Ethics committee.

Exercise rats $(\mathrm{EX}, \mathrm{n}=10)$ were habituated to a treadmill for a total of $30 \mathrm{~min}$ on 3 subsequent days. Exercise rats ran for a total of 30days at $5 \mathrm{~m} / \mathrm{min} 5 \%$ incline for the first 5days and then progressively trained to run $10 \mathrm{~m} / \mathrm{min} 5 \%$ incline bi-daily (at $0900 \mathrm{~h}$ and $1530 \mathrm{~h}$ ) for a cumulative total of 30min for 5weeks (protocol amended from [15]). The treadmill was a purpose built 8 lane exercise treadmill with dividing walls suspended over the tread surface and was cleaned with $70 \%$ alcohol after each rat's exercise session. EX rats were run in teams with their cage mates. Control rats $(\mathrm{CON}, \mathrm{n}=9)$ were handled daily for approximately $5 \mathrm{~min}$ each. At the end of this training period behavioural analysis commenced. All testing was performed during daylight hours (between 9am and 3pm) under 300lux lighting in a randomised cohort order in the below test order with $24 \mathrm{~h}$ between tests.

In the social interaction test an EX or CON rat was placed in the test arena (black wooden box, $60 \mathrm{~cm}$ long $\mathrm{x} 60 \mathrm{~cm}$ wide $\mathrm{x} 50 \mathrm{~cm}$ high, rats placed nose to opposing corners) with a previously unknown 'target' rat for $10 \mathrm{~min}$ to observe social interaction. All sessions were videotaped for analysis of active social interaction (sniffing, grooming, following, or crawling over/under within $5 \mathrm{~cm}$ of the target rat), passive social interaction (defined as the experimental rat being within $2 \mathrm{~cm}$ of the target rat but not actively interacting) or no interaction, was carried out for the $10 \mathrm{~min}$ interaction period $[13,16]$. Experimenters were blind to treatment condition.

The elevated plus maze, elevated $70 \mathrm{~cm}$ above the ground, consisted of two open arms $(70 \times 10 \mathrm{~cm})$ and two enclosed arms $(70 \times 10 \mathrm{~cm})$ with a $25 \mathrm{~cm}$ high surrounding clear Perspex wall, with the arms 
extending from a central platform $(13 \times 13 \mathrm{~cm})$. Rats were placed individually on the maze in the

centre platform, nose facing the closed arm. Behaviour was measured for $5 \mathrm{~min}$ and videotaped for subsequent analysis of arm entries and time in arms. Experimenters were blind to treatment condition.

Locomotor activity was performed using a Med Associates (USA) open field test chamber $(44.5 \mathrm{~cm}$ $\mathrm{x} 44.5 \mathrm{~cm} \times 30.5 \mathrm{~cm})$ as previously described [17]. Rats were placed individually in the test chamber for 10mins with analysis of total distance travelled and average velocity performed by Med Associates (USA) activity monitor software, version 4.

Rats received a lethal dose of sodium pentobarbital ( $1 \mathrm{ml} / \mathrm{kg}$ body weight). Brains were removed with the left hemisphere fixed in 4\% paraformaldehyde in PBS and the right hemisphere frozen in isopentane (Sigma-Aldrich) cooled to $-35^{\circ} \mathrm{C}$ by dry ice. Serial coronal sections $(30 \mu \mathrm{m})$ from the left hippocampus (bregma $-3.3 \mathrm{~mm}$ ) were processed for parvalbumin immunohistochemistry as previously described [16]. In brief sections were incubated in $0.6 \%$ hydrogen peroxide solution followed by $5 \%$ normal horse serum with $0.1 \%$ Triton X-100. Following a 36hour incubation with parvalbumin antibody (Swant, Switzerland; 1:10,000) and 2hour incubation in biotinylated antimouse IgG, sections were processed by the avidin-biotin method using a Vectastain ABC kit (Vector Laboratories, UK) and visualised using 3', 3'-diaminobenzidine (DAB) intensified with nickel chloride. Sections were mounted and allowed to dry overnight before being dehydrated and coverslipped.

For image analysis sections from each rat were captured at 40x magnification using a Nikon Eclipse 90i microscope interfaced with NIS-Elements Advanced Research 3.21.000 (Build 689) via a Nikon D-Eclipse $\mathrm{C} 1$ camera. Manual counting of parvalbumin-immunoreactive neurons using Image $\mathbf{J}$ was carried out for dentate gyrus (DG), CA1 and CA2/CA3 subregions, with the entire extent of the target region within the selected coronal sections assessed. Counts were taken from at least four alternate sections from each hemisphere, and these counts then averaged to produce a mean. All data are presented as mean \pm standard error of the mean (SEM). Social interaction, elevated plus maze data and parvalbumin levels are analysed by multivariate ANOVA (SPSS, version 19, IBM, 
USA) and where appropriate with simple effects. Locomotor activity was assessed by t-test (SPSS,

version 19, IBM, USA).

Low intensity treadmill exercise had a significant effect on sociability behaviour. While there was no overall observed effect of group $\left(\mathrm{F}_{(1,17)}=2.6, p=0.13\right)$, a significant difference in the type of behaviour $\left(\mathrm{F}_{(1,17)}=60.9, p<0.0001\right)$ and group $\mathrm{x}$ behaviour interaction $\left(\mathrm{F}_{(1,17)}=7.4, p<0.05\right)$ was observed. Posthoc analysis showed that EX animals did not differ in their active behaviour scores $(\mathrm{F}<1)$, but were more likely to passively interact with the target rat, that is to be in close proximity to it $\left(\mathrm{F}_{(1,51)}=4.8, p<0.05\right)$ without moving away and avoiding contact with it $\left(\mathrm{F}_{(1,17)}=13.5, p=0.005\right)$ than the CON animals who were not exercised (Figure 1).

Exercise did not affect anxiety levels with EX and CON animals performing similarly on the elevated plus maze. Considering arm entries (open: EX 4.2 \pm 0.4 , CON 3.2 \pm 0.4 ; closed: $6.8 \pm 0.4$, CON 6.3 \pm 0.5$)$ there was no group $\left(\mathrm{F}_{(1,17)}=2.2, p=1.6\right)$, nor group $\mathrm{x}$ arm interaction $(\mathrm{F}<1)$. Both groups of rats had significantly more entries into the closed arms than the open $\left(\mathrm{F}_{(1,17)}=45.8\right.$, $p<0.001)$ and this was not different between the $\mathrm{EX}$ and $\mathrm{CON}$ rats $(\mathrm{F}<1)$. In addition, for time (sec) spent in the arms (open: EX 82.4 \pm 11.3 , CON 71.0 \pm 9.8 ; closed: $217.6 \pm 11.3, \mathrm{CON} 229.0 \pm 9.8$ ), there was no group $(\mathrm{F}<1)$, nor group $\mathrm{x}$ arm interaction $(\mathrm{F}<1)$. Both groups of rats spent significantly more time in the closed arms than the open $\left(\mathrm{F}_{(1,17)}=90.2, p<0.001\right)$ and again this was not different between the EX and $\mathrm{CON}$ rats $(\mathrm{F}<1)$ (Figure 2).

All rats exhibited equivalent basal locomotor function irrespective of being exposed to low intensity exercise (distance travelled: EX 1527 $\pm 132, \mathrm{CON} 1598 \pm 127 ; p=0.71$; average speed: EX 47.6 \pm 2.2 , CON 49.9 $+8.6 ; p=0.52)$.

Exercise significantly increased the number of parvalbumin-immunoreactive neurons in the hippocampus. Significant changes were observed between EX and CON $\left(\mathrm{F}_{(1,16)}=14.0, p<0.01\right)$; hippocampal region $\left(\mathrm{F}_{(1,16)}=197.0, p<0.001\right)$, and their interaction $\left(\mathrm{F}_{(1,16)}=9.0, p<0.01\right)$. Posthoc analysis showed that EX animals had significantly raised parvalbumin immunoreactivity in CA1 $\left(\mathrm{F}_{(1,48)}=34.7, p<0.001\right)$ and $\mathrm{CA} 2 / 3$ region $\left(\mathrm{F}_{(1,48)}=5.5, p<0.05\right)$, but not $\mathrm{DG}(\mathrm{F}<1)$ (Figure 3). 
This study demonstrates for the first time that low-intensity treadmill running has significant effects

on social behaviour in the rat. This effect is observed with no concurrent changes in general anxiety or locomotor measures, but with an observed increase in parvalbumin-immunoreactive hippocampal neurons.

Social interaction measures social and explorative behaviours between unfamiliar pairs of rats and has been repeatedly validated as a measure of anxiety-related behaviour, assessing both anxiolytic and anxiogenic effects [13]. Treadmill exercise produced a reduction in the social anxiety observed when pairing an exercised animal with a previously unknown 'target' animal. We observed less social withdrawal in the EX animals in response to the 'target' rat compared to unexercised controls, and an increase in 'passive' interaction where there is a higher level of non-active contact with the unknown 'target' rat. This observed increase in social interaction, observed without an associated increase in locomotor activity or difference in movement on the elevated plus maze, is indicative of an anxiolytic effect of exercise on social behaviour [13].

While there is much anecdotal qualitative evidence observed in humans of the benefits of exercise in decreasing anxiety and other psychiatric symptoms [12], this is the first observation of improved sociality after treadmill exercise in normal rats. Indeed the observations of any exercise on social interaction in rodents is limited and varied: two week voluntary exercise in mice also produced an increase in social contact [18], conversely in Spontaneously Hypertensive Rats a similar exercise regime reduced the number of social interactions, at least in females [19].

When using the elevated plus-maze test we demonstrated no differences in behaviour between our EX and CON rats. This is consistent with other reported studies using low intensity physical treadmill training, as we have used here, in so-called 'normal' adult rats $[20,21]$. However it is clear that beneficial effects of exercise are observed in animal models of impairment in terms of reducing anxiety. Exercise has been reported to decrease anxiety in aged rats [22]; rodent models of neurological disease such as Parkinson's disease [23] and attention hyperactivity deficit disorder [24]; and stressed rats [25]. Moreover, it must be recognised that environmental enrichment, which 
has a large voluntary exercise component, consistently produces an anxiolytic effect in rodents [26,

27].

Treadmill training in rodents offers a consistent exercise protocol between subjects. Our results in both the social interaction and elevated plus-maze negate the suggestion that forced treadmill running may issue a long-term physiological anxiety or stress response, which is validated by studies showing no difference in plasma corticosterone or adrenocorticotropic hormone levels in rats between forced and voluntary running [28]. Moreover the beneficial effects of endurance training on the brain suggests its importance in neuroprotection, including antioxidative properties [29] and decreases in neuronal apoptosis [30].

We demonstrate an increase in parvalbumin immunoreactive neurons in the CA1 and CA2/3 regions of the hippocampus after training on the treadmill. This is consistent with the findings of other researchers investigating this class of neurons and voluntary or treadmill exercise $[7,14,31]$. Parvalbumin inhibitory interneurons are essential for information processing and play a crucial role in controlling excitatory transmission in the hippocampal neurons [32]. Indeed, exercise is well recognised to enhance hippocampal neurogenesis [3].

A possible association between the increased pattern of PV staining in our exercised group and the anxiolytic results obtained from the social behaviour test are difficult to interpret at this stage. We have previously demonstrated impaired social behaviour, exhibited by increased following of the 'target' rat, after subchronic phencyclidine administration that is also accompanied by a decrease in PV-labelled hippocampal neurons in rats [16]. In a recent study prenatal ethanol exposure with neural stem cell treatment reversed a deficit in both PV-labelled GABAergic interneurons and social interaction behaviour [33], suggesting a role for PV-containing GABAergic interneurons in the behavioural abnormalities of social dysfunction.

The beneficial effects of exercise on brain health are widely recognized. Clinical studies have highlighted that exercise enhances cognitive functions, reduces the risks of age-related cognitive impairment [1], and exerts antidepressant effects in mildly to moderately depressed [11]. Social withdrawal and loss of parvalbumin immunoreactive neurons are one of the primary pathologies 
evident in schizophrenia [34] and also in bipolar disorder [35] suggesting that physical exercise may

1 have important positive physiological as well as psychological effects in psychiatric disorders [12].

In conclusion, the present study has shown that low intensity treadmill exercise has anxiolytic effects on social behaviour, while concurrently increasing neuron numbers within the hippocampus; demonstrating further the positive effects of exercise on the brain. 


\section{Acknowledgements}

1 Jason Nguyen holds an Australian Postgraduates Award (APA) Postgraduate Scholarship. We

3 thank Professor Hawley for the use of the rat treadmill. 


\section{Figure Legends}

\section{Figure 1}

Social interaction after low impact treadmill exercise of exercised (EX) and control (CON) rats.

Data are expressed as mean interaction scores \pm SEM, $n=9-10$ /group. ${ }^{*} p<0.05 ; * * * p=0.001$.

\section{Figure 2}

Elevated plus maze data after low impact treadmill exercise of exercised (EX) and control (CON) rats. A: Number of arm entries in open and closed arms. B: Time spent in open and closed arms (sec). Data are expressed as mean \pm SEM, $n=9$-10/group.

\section{$\underline{\text { Figure } 3}$}

A: Number of Parvalbumin immunoreactive neurons in the CA1, CA2/3 and dentate gyrus (DG) regions of the hippocampus of exercised $(\mathrm{EX})$ and control $(\mathrm{CON})$ rats. Data are expressed as mean number of immunoreactive neurons \pm SEM, $n=8$-10/group. ${ }^{*} p<0.05$; $* * * p<0.001$. B: Parvalbumin immunoreactivity in the rat hippocampus of EX rats. C: Parvalbumin immunoreactivity in the rat hippocampus of CON rats. Brightfield photomicrograph of coronal section showing the distribution of parvalbumin immunoreactivity throughout the hippocampus. $4 \times$ magnification. Arrows designate parvalbumin-labelled neurons. 


\section{References}

[1] Hopkins ME, Davis FC, Vantieghem MR, Whalen PJ, Bucci DJ. Differential effects of acute and regular physical exercise on cognition and affect. Neuroscience. 2012;215:59-68.

[2] Coelho FG, Andrade LP, Pedroso RV, Santos-Galduroz RF, Gobbi S, Costa JL, et al. Multimodal exercise intervention improves frontal cognitive functions and gait in Alzheimer's disease: A controlled trial. Geriatr Gerontol Int. 2012;13:198-203.

[3] van Praag H, Christie BR, Sejnowski TJ, Gage FH. Running enhances neurogenesis, learning, and long-term potentiation in mice. Proceedings of the National Academy of Sciences of the United States of America. 1999;96:13427-31.

[4] Sohal VS, Zhang F, Yizhar O, Deisseroth K. Parvalbumin neurons and gamma rhythms enhance cortical circuit performance. Nature. 2009;459:698-702.

[5] Kawaguchi Y, Katsumaru H, Kosaka T, Heizmann CW, Hama K. Fast spiking cells in rat hippocampus (CA1 region) contain the calcium-binding protein parvalbumin. Brain research. 1987;416:369-74.

[6] Celio MR. Calbindin D-28k and parvalbumin in the rat nervous system. Neuroscience. 1990;35:375-475.

[7] Arida RM, Scorza CA, da Silva AV, Scorza FA, Cavalheiro EA. Differential effects of spontaneous versus forced exercise in rats on the staining of parvalbumin-positive neurons in the hippocampal formation. Neuroscience letters. 2004;364:135-8.

[8] Bender T, Nagy G, Barna I, Tefner I, Kadas E, Geher P. The effect of physical therapy on betaendorphin levels. Eur J Appl Physiol. 2007;100:371-82.

[9] Goekint M, Bos I, Heyman E, Meeusen R, Michotte Y, Sarre S. Acute running stimulates hippocampal dopaminergic neurotransmission in rats, but has no influence on brain-derived neurotrophic factor. J Appl Physiol. 2012;112:535-41.

[10] Gomez-Merino D, Bequet F, Berthelot M, Chennaoui M, Guezennec CY. Site-dependent effects of an acute intensive exercise on extracellular 5-HT and 5-HIAA levels in rat brain. Neuroscience letters. 2001;301:143-6. 
[11] Martinsen EW. Benefits of exercise for the treatment of depression. Sports Med. 1990;9:380-9.

[12] Wolff E, Gaudlitz K, von Lindenberger BL, Plag J, Heinz A, Strohle A. Exercise and physical activity in mental disorders. European archives of psychiatry and clinical neuroscience. 2011;261 Suppl 2:S186-91.

[13] File SE, Seth P. A review of 25 years of the social interaction test. European journal of pharmacology. 2003;463:35-53.

[14] Gomes da Silva S, Dona F, da Silva Fernandes MJ, Scorza FA, Cavalheiro EA, Arida RM. Physical exercise during the adolescent period of life increases hippocampal parvalbumin expression. Brain Dev. 2010;32:137-42.

[15] Lessard SJ, Rivas DA, Stephenson EJ, Yaspelkis BB, 3rd, Koch LG, Britton SL, et al. Exercise training reverses impaired skeletal muscle metabolism induced by artificial selection for low aerobic capacity. Am J Physiol Regul Integr Comp Physiol. 2011;300:R175-82.

[16] Jenkins TA, Harte MK, McKibben CE, Elliott JJ, Reynolds GP. Disturbances in social interaction occur along with pathophysiological deficits following sub-chronic phencyclidine administration in the rat. Behavioural brain research. 2008;194:230-5.

[17] Jenkins TA, Elliott JJ, Ardis TC, Cahir M, Reynolds GP, Bell R, et al. Tryptophan Depletion Impairs Object Recognition Memory In The Rat: Reversal By Risperidone. Behavioural brain research. 2009;209:478-483.

[18] Salam JN, Fox JH, Detroy EM, Guignon MH, Wohl DF, Falls WA. Voluntary exercise in C57 mice is anxiolytic across several measures of anxiety. Behavioural brain research. 2009;197:31-40. [19] Hopkins ME, Sharma M, Evans GC, Bucci DJ. Voluntary physical exercise alters attentional orienting and social behavior in a rat model of attention-deficit/hyperactivity disorder. Behavioral neuroscience. 2009;123:599-606.

[20] Cordova SD, Loss CM, de Oliveira DL. Low-intensity physical training recovers object recognition memory impairment in rats after early-life induced Status epilepticus. Int J Dev Neurosci. 2013;31:196-201. 
[21] Burghardt PR, Fulk LJ, Hand GA, Wilson MA. The effects of chronic treadmill and wheel

running on behavior in rats. Brain research. 2004;1019:84-96.

[22] Pietrelli A, Lopez-Costa J, Goni R, Brusco A, Basso N. Aerobic exercise prevents agedependent cognitive decline and reduces anxiety-related behaviors in middle-aged and old rats. Neuroscience. 2012;202:252-66.

[23] Gorton LM, Vuckovic MG, Vertelkina N, Petzinger GM, Jakowec MW, Wood RI. Exercise effects on motor and affective behavior and catecholamine neurochemistry in the MPTP-lesioned mouse. Behavioural brain research. 2010;213:253-62.

[24] Ko IG, Kim SE, Kim TW, Ji ES, Shin MS, Kim CJ, et al. Swimming exercise alleviates the symptoms of attention-deficit hyperactivity disorder in spontaneous hypertensive rats. Molecular medicine reports. 2013;8:393-400.

[25] Lapmanee S, Charoenphandhu N, Krishnamra N, Charoenphandhu J. Anxiolytic-like actions of reboxetine, venlafaxine and endurance swimming in stressed male rats. Behavioural brain research. 2012;231:20-8.

[26] Nithianantharajah J, Hannan AJ. Enriched environments, experience-dependent plasticity and disorders of the nervous system. Nature reviewsNeuroscience. 2006;7:697-709.

[27] Larsson F, Winblad B, Mohammed AH. Psychological stress and environmental adaptation in enriched vs. impoverished housed rats. Pharmacology, biochemistry, and behavior. 2002;73:193207.

[28] Boersma GJ, Barf RP, Benthem L, van Dijk G, Scheurink AJ. Forced and voluntary exercise counteract insulin resistance in rats: The role of coping style. Horm Behav. 2012; 62:92-98.

[29] Cechetti F, Worm PV, Elsner VR, Bertoldi K, Sanches E, Ben J, et al. Forced treadmill exercise prevents oxidative stress and memory deficits following chronic cerebral hypoperfusion in the rat. Neurobiol Learn Mem. 2012;97:90-6.

[30] Itoh T, Imano M, Nishida S, Tsubaki M, Hashimoto S, Ito A, et al. Exercise inhibits neuronal apoptosis and improves cerebral function following rat traumatic brain injury. J Neural Transm. 2011;118:1263-72. 
[31] Hwang IK, Yi SS, Yoo KY, Park OK, Yan B, Song W, et al. Differential effects of treadmill exercise in early and chronic diabetic stages on parvalbumin immunoreactivity in the hippocampus of a rat model of type 2 diabetes. Neurochem Res. 2011;36:1526-32.

[32] Miles R, Wong RK. Single neurones can initiate synchronized population discharge in the hippocampus. Nature. 1983;306:371-3.

[33] Shirasaka T, Hashimoto E, Ukai W, Yoshinaga T, Ishii T, Tateno M, et al. Stem cell therapy: social recognition recovery in a FASD model. Translational psychiatry. 2012;2:e188.

[34] Zhang ZJ, Reynolds GP. A selective decrease in the relative density of parvalbuminimmunoreactive neurons in the hippocampus in schizophrenia. Schizophrenia research. 2002;55:110.

[35] Reynolds GP, Abdul-Monim Z, Neill JC, Zhang ZJ. Calcium binding protein markers of GABA deficits in schizophrenia--postmortem studies and animal models. Neurotoxicity research. 2004;6:57-61. 
Click here to download high resolution image

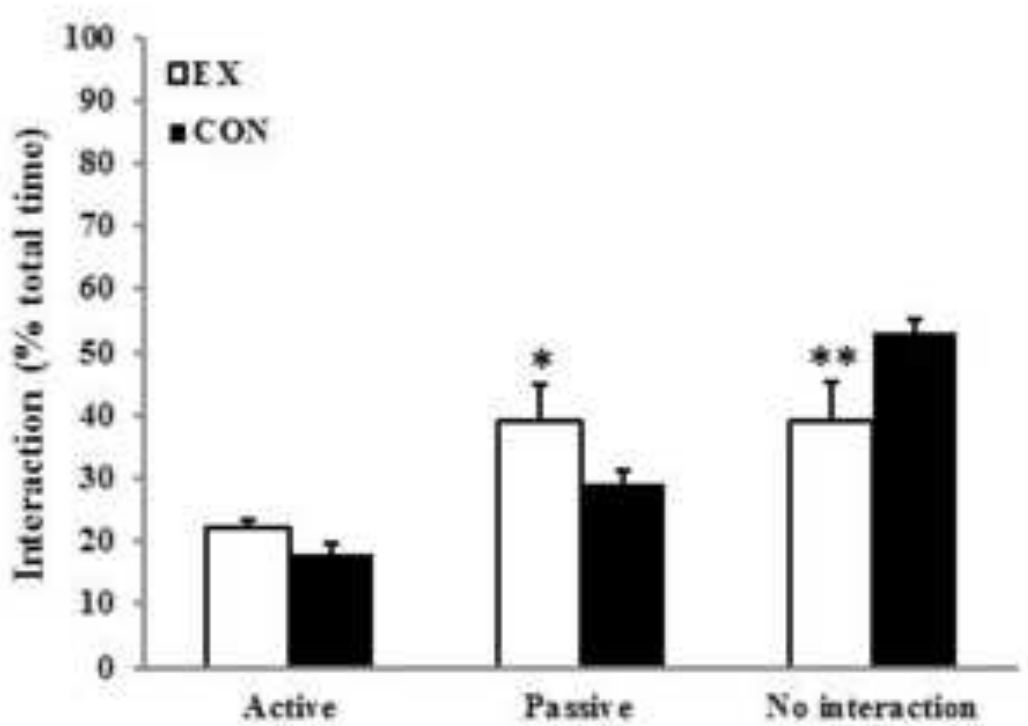



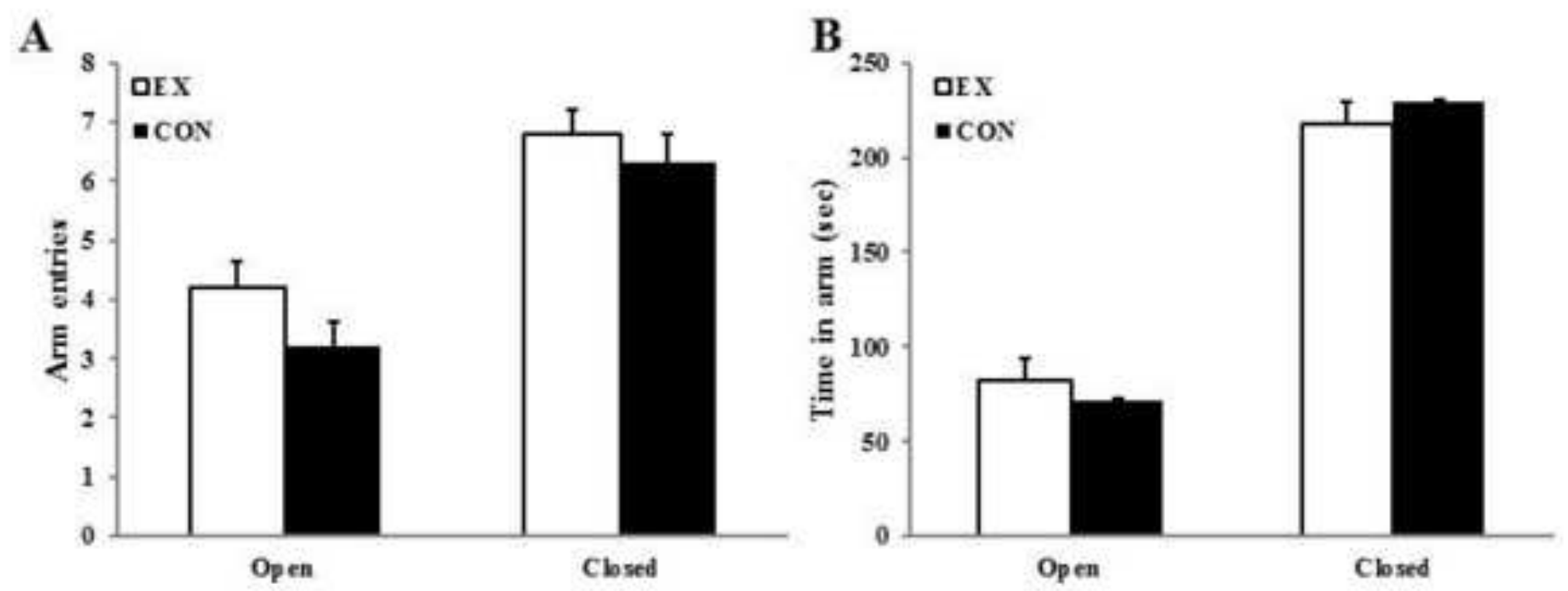
A

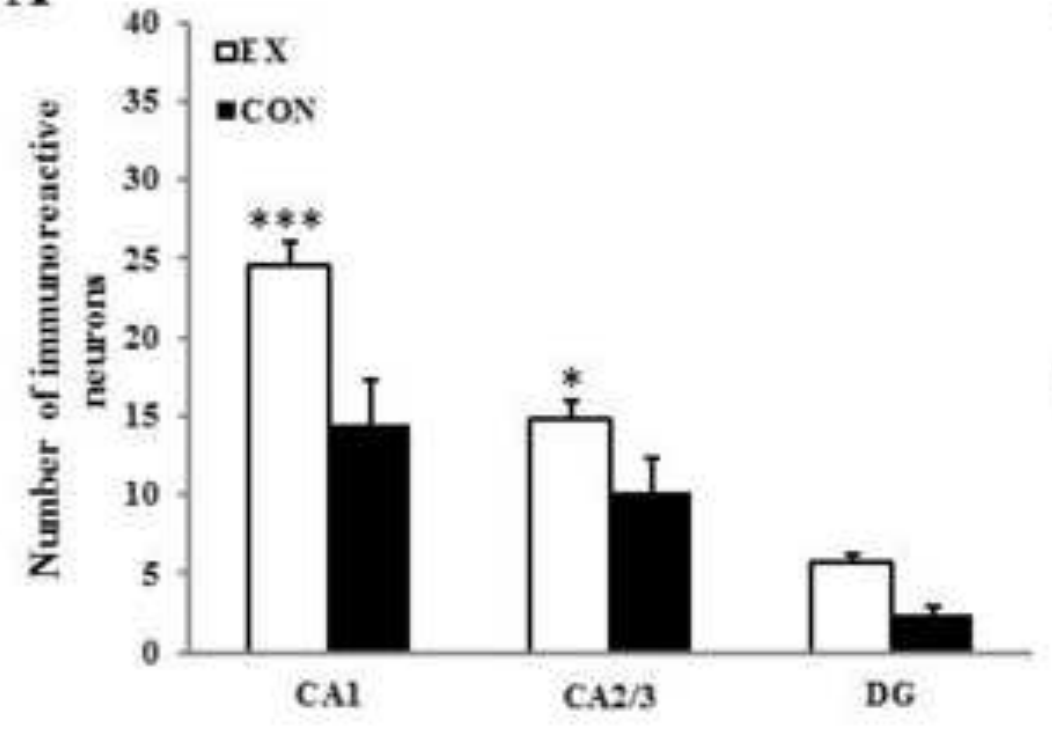

B

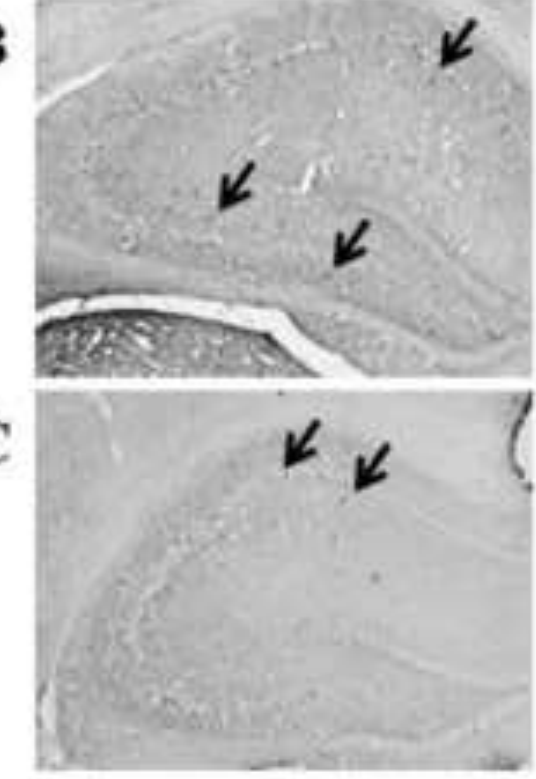

